\title{
La piedra ha florecido en islas: recordando la vida y obra de Kamau Brathwaite (1930-2020)
}

The Stone had bloomed into ISLANDS: REMEMbering THE Life AND WORKS OF KaMAu BrathWaite (I930-2020)

\author{
Thomas Rothe \\ Universidad de Chile \\ thomasrothe@ug.uchile.cl
}

En su poema "Calypso", de 1967, Kamau Brathwaite articula una relación entre escritura, música popular y cosmogonía caribeña que vendría a sostener sus influyentes conceptualizaciones sobre lenguaje e identidad. Los versos construyen un mito de génesis guiados por el ritmo familiar del calypso o kaiso, género musical originario de Trinidad y Tobago y predominante a lo largo del Caribe anglófono. De esta forma, ofrece una fórmula de escritura que rompe con el pentámetro yámbico, inculcado en generaciones de escolares a través de la educación colonial británica. Mientras la lectura del texto insinúa esta conexión, es la voz de Brathwaite recitando/cantando lo que permite entrar en una experiencia más holística del poema. Basta leer las primeras estrofas y escuchar la grabación que hizo la disquera Argo de 1968 ("Calypso...") para empezar a comprender los múltiples factores en juego aquí: 


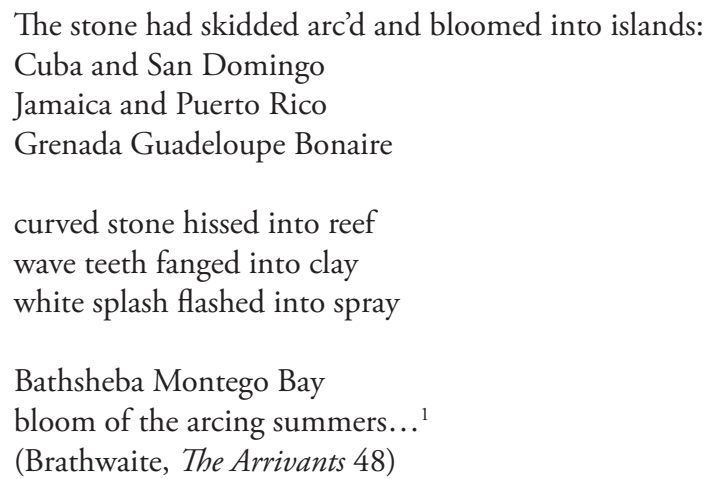

Este poema está en el centro del concepto de nation language (lenguaje-nación) que introdujo Brathwaite para sustituir el término de dialecto y valorar el habla cotidiana como una manera de reforzar las identidades culturales caribeñas. Con todas las ambigüedades que deja el concepto de lenguaje-nación -siendo aplicable al creole y al inglés estándar con acento caribeño (Rothe 230-231)-, Brathwaite abre camino para la búsqueda de una expresión autóctona que reconoce y celebra la herencia africana como una de las bases más importantes de la conformación sociocultural de la región. Por eso el poema conecta el pasado con el presente para imaginar un futuro posible, sin las amarras residuales del colonialismo, un proceso escritural que el mismo Brathwaite ha descrito de la siguiente manera: "Es muy importante reconocer que cada ritmo, cada metáfora, cualquier cosa originaria es el símbolo silencioso de algo mucho más profundo, mucho más originario, que, al comenzar a relacionarte con él, te conduce al futuro de su realidad escrita” (cit. en Phaf-Rheinberger 315-316). En este poema/canción, Brathwaite recobra su concepto de "inteligencia silábica” (La unidad 121) que permite definir una consciencia de lugar

1 La primera versión al español del poema vino de la pluma del poeta y traductor cubano David Chericián, publicada en la revista Casa de las Américas en 1980: "La piedra ha resbalado en arco y florecido en islas: / Cuba y Santo Domingo / Jamaica y Puerto Rico / Granada Guadalupe Bonaire // piedra curva que silva hacia los riscos / dientes de olas prendidos a la arcilla / blanca espuma que en átomos se astilla // Betsabé Montego Bay orillas / arqueado florecer de los veranos..." (100). Si bien no logra trasladar al espańol todas las implicancias semánticas presentes en el original, esta versión se guía por cierta estructura sonora, como se evidencia en las rimas. 
en el mundo, la capacidad de no solo describir la experiencia foránea de la caída de la nieve, sino el huracán que interrumpe la vida en el Caribe todos los años. Se trata de un pequeño paso para descolonizar la lengua, conectar las esferas letradas con los segmentos populares, entender la tradición oral como depositaria de un conocimiento milenario que sobrevivió al desplazamiento forzado desde África y la esclavitud americana.

La muerte de Edward Kamau Brathwaite, el 4 de febrero de 2020, se suma a un conjunto de pérdidas recientes en el mundo de las letras caribeńas y latinoamericanas: Roberto Fernández Retamar, Ernesto Cardenal, Derek Walcott, Gabriel García Márquez, autores y personajes que marcaron las corrientes de pensamiento y cultura de nuestra América en la segunda mitad del siglo XX. En todos estos casos, la partida era relativamente esperada, por el desgaste del tiempo sobre el cuerpo, pero nada nos prepara para el abrupto final: la verdadera irreversibilidad de la muerte, que deja una ausencia en la obra de autores que, de habernos acompañado durante años, ya parecen viejos amigos. Sus libros son las huellas que dejan, sus ideas siguen despertando nuevos estímulos, ofreciendo miradas a ciertas épocas pasadas y modelos para seguir o, en algunos casos, cuestionar.

El impacto de Brathwaite sobre la literatura y el pensamiento crítico del Caribe desborda cualquier intento de resumen. Su vida y obra dejan tantos aportes, entre historiografía, propuestas teóricas, poesía que echa raíces en las culturas populares del Caribe y vuela por los cosmos -o las profundidades submarinas- de la imaginación. En su vasta obra poética, se destacan Rights of Passage (1967), Masks (1968) y Islands (1969), publicado como trilogía bajo el título The Arrivants (1973); Black + Blues (1976), Third World Poems (1983), X/Self (1986), Middle Passages (1992), Trench Town Rock (1992), Barabajan Poems (1994), Dream Stories (1994), Words Need Love Too (2000), Ancestors (2001), MR (Magical Realism) (2002), Elegguas (2010), Strange Fruit (2016), Liviticus (2017) y The Lazarus Poems (2017), entre muchos otros. Además de las becas obtenidas de las fundaciones Guggenheim, Fulbright y Ford, Brathwaite recibió numerosos premios que incluyen el Premio de Poesía Griffin en 2006 por su libro Born to Slow Horses (2006) y el Premio de Poesía PEN/Voelcker. A pesar de recibir el premio Casa de las Américas en cuatro ocasiones, su obra poética es 
escasamente accesible en castellano, salvo por poemas sueltos publicados en la revista homónima, el volumen Black + Blues y la antología Los danzantes del tiempo, ambos libros ganadores del premio en 1976 y 2011, respectivamente.

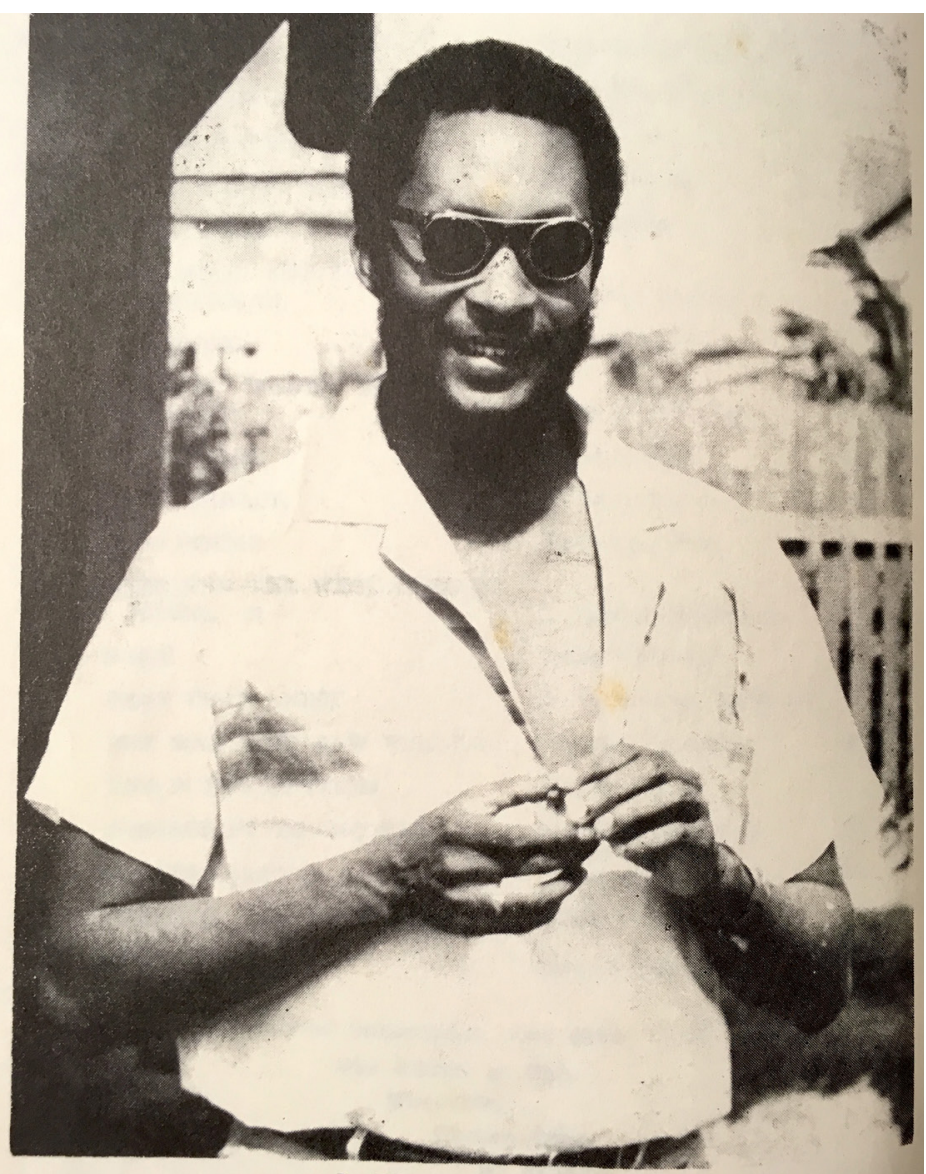

L. Edward Brathwaite.

IMAGEN I: Foto de un joven Brathwaite.

Fuente: $B I M$, vol. 12, no 45, 1967, p. iv. 
Lawson Edward Brathwaite nació en 1930 en Bridgetown, capital de Barbados, la más expuesta al Atlántico de las islas de Barlovento. A los veinte ańos, comenzó a publicar poemas en BIM, la famosa revista barbadense dirigida por Frank Collymore, una leyenda en la formación del canon literario anglocaribeńo. Aparte de ser una valiosa plataforma de publicación en el exiguo escenario literario barbadense de esa época, $B I M$ ofreció una comunidad literaria compuesta por otros jóvenes autores inquietos, entre ellos Derek Walcott y George Lamming, y también un espacio de aprendizaje proporcionado por Collymore, quien aparece ficcionalizado como el director de escuela en la novela En el castillo de mi piel de Lamming. En 1951, Brathwaite partió a Inglaterra becado para estudiar Historia en la Universidad de Cambridge. En este periodo participó en el influyente programa de radio de la BBC Caribbean Voices, donde entró en contacto con otros escritores caribeños residentes en Inglaterra, como los trinitarios V.S. Naipaul y Samuel Selvon. Después de graduarse en 1955, viajó a Ghana para trabajar en el Ministerio de Educación inglés, quedándose hasta el comienzo de la década de los sesenta. Estos años fueron decisivos en su formación porque permitieron una entrada al conocimiento africano en relación con sus orígenes y la influencia en las culturas del Caribe. Años después, adoptaría el nombre "Kamau", con el que firma la mayoría de su obra, que proviene del idioma kikuyu de Kenia y que significa "guerrero silencioso".

El silencio no es algo frecuentemente asociado a Brathwaite: la tradición oral y la música afrocaribeńa y afroamericana en general constituyen grandes fuentes de inspiración en su obra. Sobre el lenguaje-nación, él mismo explica que es fundamental comprender que existe una conexión "entre las estructuras musicales nativas y la lengua nativa. Que la música es, de hecho, el umbral más seguro del lenguaje que sale de ahí" (La unidad submarina 129). No por nada, en un temprano ensayo, "Jazz and the West Indian Novel", explora la relación entre la novela anglocaribeña y ciertas estructuras musicales del jazz. Kwame Dawes ha comentado que la música afroamericana -en el más amplio sentido de la palabra- permitió que Brathwaite se vinculara con el paisaje y la cultura de su propia gente, los afrodescendientes en el Caribe y la diáspora, siendo un punto de referencia constante en su tránsito desde una educación eurocéntrica, pasando por un periodo afrocéntrico, hasta llegar a poner en marcha un proceso creativo que se apropia de una diversidad de fuentes culturales (66-67). 
Lejos de reducirse a una simple mímesis del habla cotidiano, la escritura de Brathwaite constituye una puesta en escena autorial para construir textos polifónicos que tratan el colonialismo y su relación con el lenguaje. Esto se ve potenciado por la apuesta visual que utiliza desde los noventa: una serie de tipografías no convencionales llamada Sycorax video-style, nombre que alude a la madre invisible de Calibán, personaje de la última obra de teatro de Shakespeare, La Tempestad, que, por tocar temas de colonización y esclavitud en una isla sin nombre, marca una omnipresencia en la crítica cultural caribeña. Caracterizada por letras de distintos tamańos y fuentes, organizadas a veces caóticamente por la página y con una deletreo no convencional, este estilo busca estallar los confines de la tradicional escritura occidental, que Brathwaite identifica con las cualidades del personaje Próspero. La entrada al mundo digital y la experimentación con los distintos tipos de letras representó un pulso vanguardista en los años noventa, abriendo otra vez inéditas posibilidades para la escritura del Caribe. Sin embargo, la insistencia con este estilo en sus obras posteriores, entrado ya el siglo XXI digitalizado, a veces resulta abrumador, anticuado y difícil de penetrar.

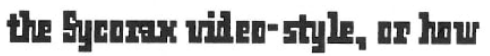

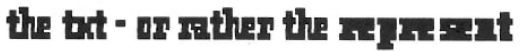 차ㄴㅜㅛ iㅡ the SOUnd nit - its Singer -

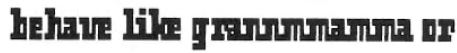
uituh $\mathbf{t}$ alihans Enation. -land uarte, parulins, sam-

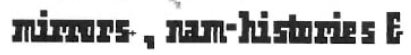
-hertumifs gatives alteryatives

IMAGen 2: Ejemplo de Sycorax video-style.

Fuente: Brathwaite, Kamau, MR (Magical Realism), p. 112. 
Historiador de profesión, Brathwaite ha contribuido con estudios fundamentales a la historiografía caribeña, como The Development of Creole Society in Jamaica, 1770-1820 (1971), resultado de su tesis de doctorado que realizó en la Universidad de Sussex, Inglaterra. El libro levanta valiosa información sobre el periodo estudiado y plantea una serie de tesis sobre los efectos psicológicos y culturales del colonialismo en Jamaica. Pero la historia en la obra de Brathwaite no se desarrolla dentro de los límites de la disciplina, es más bien una manera de hacer poesía al tiempo que la poesía es una manera de hacer historia. La búsqueda de los orígenes es un elemento clave en esta mezcla genérica: África, el Middle Passage, la esclavitud y sus influencias en la experiencia del Caribe contemporáneo son los motores del trabajo artístico e intelectual de Brathwaite, que rellena vacíos históricos y plantea interrogantes que dejan ver nuevos vacíos.

En el área de la crítica, Brathwaite tiene una trayectoria sólida y consistente. A mediados de los años sesenta, junto a John La Rose y Andrew Salkey, fundó el Caribbean Artists Movement (CAM), que agrupaba a artistas y escritores ubicados principalmente en Londres para estimular cambios de paradigma en la producción cultural caribeña. Un foco de interés del CAM fue la necesidad de eliminar barreras entre los sectores letrados y populares del Caribe, tanto en la región como en la diáspora, y las reuniones que organizaba reflejan esta diversa composición, contando con la presencia de migrantes obreros, estudiantes de postgrados, escritores y pintores. La importancia del CAM para el desarrollo cultural e intelectual del Caribe anglófono no puede ser subestimada: significó un quiebre con los modelos culturales tradicionales, legados del colonialismo británico, y propuso nuevas formas de pensar y entender la identidad cultural a partir del conocimiento popular y la reivindicación afrodescendiente. Esta posición se difundió a una escala mayor a través de Savacou, la revista oficial del CAM, que dirigieron Brathwaite y Kenneth Ramchand desde Kingston a lo largo de los setenta. Savacou fue una pieza fundamental en el giro que tomaría el desarrollo literario anglocaribeño, alentando propuestas estéticas que combinaran escritura y oralidad, la estética reggae y la cosmovisión rastafari, además de nuevos modelos críticos. Entre sus páginas, vemos colaboraciones de algunos de los más destacados intelectuales de la región, como Elsa Goveia, Orlando Patterson, Marina Maxwell, Michael Anthony, George Beckford, Sylvia Wynter, C. L. R. James, Walcott, Lamming y hasta 
Nicolás Guillén, traducido al inglés, entre muchos otros. Una de las características del CAM que se refleja en su revista es la importante presencia de artistas e intelectuales mujeres, algo bastante inusual para la época. Si bien fue una iniciativa colectiva, Savacou se transformó rápidamente en una extensión del proyecto intelectual de Brathwaite, quien creó el fondo editorial homólogo para publicar libros de crítica, poesía e incluso algunas traducciones.

Aparte de su papel central en la arquitectura de estas plataformas, Brathwaite nos legó aportes conceptuales para repensar las culturas del Caribe y sus vínculos con la experiencia latinoamericana. El ya mencionado lenguaje-nación, acuñado en su presentación-ensayo "History of the Voice" ${ }^{2}$, ofrece un punto de partida contundente para contrarrestar las estigmatizaciones del habla popular. Aunque su foco es principalmente la experiencia anglófona, señala que la sumersión del lenguaje-nación ocurrió en todo el Caribe, y por lo tanto afirma que existe una unidad submarina apoyada por elementos culturales compartidos, a pesar de las diferencias lingüísticas entre los distintos países. Un ejemplo de esto se evidencia en el trabajo del filósofo y poeta martiniqueńo Édouard Glissant, quien utiliza el concepto de "poética forzada" para describir un fenómeno semejante al de lenguaje-nación, relacionándolo más a una estrategia consciente de sobrevivencia, como el lenguaje carcelario (Brathwaite Roots, 270). Esto, a su vez, se relaciona directamente con su noción de tidalectics, una manera de pensar los procesos dialécticos a través de la metáfora del fluctuante mar. En otros trabajos, como Contradictory Omens (1974), Brathwaite también desarrolla el concepto de creolización en términos similares a los utilizados por Fernando Ortiz para articular el proceso de transculturación.

Uno de los aportes de mayor envergadura en la obra crítica de Brathwaite es MR (Magical Realism) (2002), un libro de más de seiscientas páginas en el que plantea el realismo mágico como una experiencia transversal -más que género literario- del Caribe y América Latina.

2 Este trabajo fue presentado por primera vez en el Caribbean Festival of Arts (CARIFESTA) de 1976, en Jamaica, y Brathwaite utilizó grabaciones de música y poesía recitada para ejemplificar sus argumentos, aspecto que se pierde en la versión transcrita. La traducción al español de este ensayo fue realizada por Florencia Bonfiglio, incluida en el volumen La unidad submarina, junto con una versión ampliada del primer capítulo de Development of Creole Society in Jamaica y una valiosa entrevista a Brathwaite. 
Tomando las referencias fundamentales de García Márquez y Alejo Carpentier, con su concepto de lo real maravilloso, y hasta el uso alemán por Franz Roh, Brathwaite compila reflexiones críticas, anotaciones de cuaderno, poemas, extensas citas de otros escritores y mapas conceptuales, todo en su Sycorax video-style, para formar un collage particular que hace reflexionar sobre las maneras de hacer crítica cultural. El evidente diálogo que entabla el libro con América Latina es un testamento a los conatos de derribar las fronteras lingüísticas que mantienen una suerte de compartimentalización y dificultan la interacción y conocimiento mutuo con el resto del continente. Por otra parte, no puedo dejar de señalar que el libro establece una conexión especial con Chile a través de la voz de la poeta y artista visual Cecilia Vicuña, a quien Brathwaite invitaba a conversar con sus estudiantes de la Universidad de Nueva York durante los años noventa. Las citas de Vicuña reflejan coincidencias de miradas poéticas, pero también el testimonio del terror estatal vivido bajo la dictadura de Pinochet, una experiencia que conecta a Chile con el resto de América Latina y el Caribe.

Brathwaite creía que el arte debe surgir de la catástrofe, la mayor de las cuales era la esclavitud y el Middle Passage, cuyas consecuencias permean la actualidad. Sin embargo, pasó por una serie de tragedias personales que tuvieron un impacto determinante sobre su vida y obra, empezando en el periodo que llama "el tiempo de la sal". La herida más honda vino en 1986, cuando su esposa, Doris Monica Brathwaite, fue diagnosticada con un cáncer terminal y murió seis meses después, el día que cumplía sesenta ańos. Brathwaite canalizó su dolor en The Zea Mexican Diary (1993), un libro que rinde homenaje a la vida de su compañera y registra el proceso de pérdida a través de esos seis meses de angustia. Luego, en 1988, el huracán Gilbert arrasó Jamaica y en su camino quedó destruida la casa de Brathwaite en Irish Town, un pueblo arrimado a las montańas encima de Kingston. Pese a perder miles de archivos invalorables, nuevamente documentó la experiencia, en su particular poética, en el libro Shar (1990). Finalmente, en 1990, fue víctima de un asalto armado en su departamento en Kingston, donde uno de los intrusos trató de dispararle, pero el barril del arma se estancó, lo que salvó la vida material de Brathwaite, pero significó, según él mismo, su muerte espiritual. Este evento es la premisa de Trench Town Rock (1994), que comparte ciertos elementos con el intento de asesinato a Bob Marley. Si bien este "tiempo de la sal" marcó un antes 
y después en la vida de Brathwaite, tuvo que enfrentar otras desgracias que también lo condujeron hacia proyectos escriturales. Así fue con el "linchamiento cultural" que sufrió mientras residía en Nueva York: denunció que, durante cuatro ańos, alguien le robó material de trabajo y otros artículos de valor intelectual desde su departamento. Sin pruebas, la policía nunca arrestó a nadie y Brathwaite estuvo convencido de que algunas personas estaban armando un complot en su contra. Independientemente de lo estrafalario que suena, las circunstancias en torno a este momento de su vida produjeron un fantástico libro, Strange Fruit (2016), título tomado de una canción de Billie Holiday, donde establece vínculos entre el problema histórico del racismo en EE. UU. y su situación circunstancial como caribeño en Nueva York.

Abrí esta nota con el ejemplo de un temprano poema donde Brathwaite busca los signos para construir una cosmogonía caribeña. El resto de su obra, tanto crítica como poética, continúa en esa ruta, ofreciendo un punto de unión entre el arte y la teoría, pero también entre la intelectualidad letrada y el embalse de conocimiento popular. Brathwaite supo con gran inteligencia que el arte y la crítica caribeños no podrían desarrollarse negando la cultura popular, la sabiduría sumergida de las masas empobrecidas durante siglos de esclavitud. Se trata de un proyecto que tensionaba los límites de la escritura, expandiéndose constantemente hacia la esfera oral y visual en una búsqueda de identidad literaria, más colectiva que personal. Kamau Brathwaite, ahora en la tierra y el agua de su mar Caribe, se vuelve piedra, para arquearse sobre el oleaje y florecer en nuevas islas.

BibliografíA

Brathwaite, Kamau. La unidad submarina. Ensayos caribeños. Buenos Aires, Katatay Ediciones, 2010. . MR (Magical Realism). Nueva York, Savacou North, 2002. . Roots. La Habana, Casa de las Américas, 1986. UP, 1973. The Arrivants. A New World Trilogy. Oxford, Oxford BIM. Barbados, The Young Men's Progressive Club, 1942-1973. 
"Calypso Edward Brathwaite 1968". YouYube, subido por Colin Medicinehorse, 4 de diciembre de 2014. Web. Disponible en: https:// www.youtube.com/watch?v=JF7LIyp6jnI\&t=87s\&ab_channel=ColinMedicinehorse

Dawes, Kwame. Natural Mysticism. Towards a New Reggae Aesthetic. Londres, Peepal Tree Press, 2004.

Phaf-Rheinberger, Ineke (ed.). "El lenguaje-nación y la poética del acriollamiento. Una conversación entre Kamau Brathwaite y Édouard Glissant". Revista Literatura y Lingüistica, vol. 10, N 19 , 2008, pp. 311- 329.

Rothe, Thomas. Entrevista. "Lo que parece ser inglés estándar muchas veces no lo es': Una conversación sobre lengua y literatura caribeña con el poeta jamaiquino Mervyn Morris". Meridional. Revista Chilena de Estudios Latinoamericanos, $\mathrm{N}^{\circ} 10,2018$, pp. 227-238.

Savacou. Kingston, Savacou Publications, 1970-1979. 